\title{
DOSSIÊ \\ A EDUCAÇÃo PELAS IMAGENS E SUAS GEOGRAFIAS
}

\author{
Organização \\ Wenceslao Machado de Oliveira Jr
}





\section{Grafar o espaço, educar os olhos. Rumo a geografias menores}

Wenceslao Machado de Oliveira Jr*

\section{Preâmbulo poético}

No pequeno texto $O$ falhanço dos homens, o escritor português nascido em Angola, Gonçalo Tavares, escreve:

Deixa-me dizer isto: se tivesses acreditado mais no desenho do que na escrita estarias mais próximo do que é verdadeiro no Mundo.

Foi uma questão de crenças, foi uma aposta em cavalos. Os homens apostaram no cavalo errado. Eis um resumo possível da história das ciências (e não só). Porque não existem "línguas" diferentes de desenhos? Desenhos em línguas diferentes? (Tavares, 2006, p. 98)

Em certa medida, este dossiê afirma a existência de desenhos em línguas diferentes e diferentes línguas de desenhos.

Se tomarmos as imagens como grafias diversas das materialidades que gravam desenhos em superfícies quaisquer, podemos dizer que a pintura é a língua das cores a desenhar formas e sentidos, as fotografias são desenhos feitos de luz, tendo o cinema movimentado esses desenhos luminosos.

Por se darem em íntima relação com esses desenhos, com essas grafias, nossos escritos estariam mais próximos do que é verdadeiro no mundo? Ou, como se pergunta o mesmo autor português, "é mais verdadeiro desenhar o verdadeiro que escrevê-lo?" Não sabemos essas respostas. No entanto, apostamos, em nossas pesquisas e escritos, numa aproximação de parcelas do verdadeiro deste mundo atual, onde as imagens constituem muito do que nos educa os olhos e muito do que temos disponível para educarmos a nós próprios e aos nossos próximos e distantes estudantes acerca do espaço geográfico.

* Professor do Departamento de Educação, Conhecimento, Linguagem e Arte (Delart) e membro do Laboratório de Estudos Audiovisuais (Olho) da Faculdade de Educação da Unicamp, Campinas, SP, Brasil.wences@uol.com.br 


\section{Preâmbulos acadêmicos}

Nos últimos anos, a centralidade das imagens na construção do conhecimento e da formação das subjetividades tem sido assegurada por inúmeros autores, na continuidade dos estudos que apontam a dimensão cultural como central para o entendimento das sociedades contemporâneas. Na década de 1990, Stuart Hall já apontava essa centralidade da cultura, sendo a proliferação dos Estudos Culturais a marca da pertinência dessas idéias.

No campo da Educação, desde Comênio, as imagens aparecem como tendo potência educativa. Nos tempos atuais, elas não mais aparecem apenas como partícipes da criatividade e da eficiência das açôes didáticas, mas também, sobretudo, tendo em si mesmas uma dimensão pedagógica, uma potência subjetivadora e de pensamento, como o afirmam autores tão díspares e tão próximos quanto Deleuze e Pasolini.

No campo da Geografia, ao final dos anos 1970, Yves Lacoste escreveu que "hoje em dia não há mais somente a geografia dos professores, mas também aquela que veiculam a televisão, o cinema, os cartazes, os jornais...” (1981, p. 231). Vertentes mais recentes, como a Geografia Cultural e a Geografia Humanística, passaram a tomar para si as imagens como fenômenos de interesse geográfico, partindo do princípio de que elas atuam fortemente na atual partilha do sensível, realizada também nas narrativas em imagens acerca do mundo no qual vivemos.

A noção de realidade tem sido colocada de outras maneiras: muitas delas questionam, sobretudo, os amparos na visualidade, a lógica da representação e a concepção de essência; basicamente esse tem sido o caminho dos estudos pós-estruturalistas. Gianni Vattimo e Jorge Larrosa chegam, mesmo, a dizer que a realidade é o que está em discussão, constantemente construída e dissolvida pelas práticas sociais e discursivas.

Também o espaço vem tendo outras abordagens, tais como as de Doreen Massey (2008, p. 158-160), que o toma não como uma superfície, mas como "uma multiplicidade de estórias-até-agora". Podemos dizer que as imagens são parte cada vez mais intensa da multiplicidade que compóe o espaço atual.

$\mathrm{Na}$ esteira destes pensamentos, a presença das imagens é de grande importância no modo como pensamos e agimos na realidade, no espaço geográfico. Essas imagens podem ser tomadas tanto como parte das práticas discursivas signos de uma linguagem -, quanto como objetos do mundo - obras da/na cultura.

Nos últimos anos, tem se ampliado o número de pesquisas e trabalhos envolvendo as muitas linguagens nas quais o conhecimento geográfico é produzido. Tanto imagens tradicionalmente utilizadas pelos geógrafos - mapas, 
fotografias aéreas, imagens de satélite - quanto outras, menos comuns nos trabalhos geográficos - desenhos, fotografias, pinturas, cinema, televisão - passaram a ser objeto de estudo de profissionais e professores de Geografia. Alguns estudos, tais como os de Harley e sua concepção de mapa, vêm questionar a própria definição de algumas dessas imagens. Estudos como esses vêm criando devires outros no pensamento geográfico, produzindo geografias menores: estas são como ilhas no entorno do continente da geografia maior, são potências de expansão desse continente, são também as primeiras aproximações desse continente para quem vem do oceano livre e flutuante do pensamento...

\section{Educar pelas imagens}

Neste dossiê, a palavra "imagem" é sempre material, é sempre uma obra palpável aos olhos. Material porque diz de formas impressas ou presentes em telas. Palpável aos olhos porque é a eles que elas se destinam prioritariamente, são nossos olhos que elas desejam...

Educar os olhos não é somente fazê-los ver certas coisas, valorar certos temas e cores e formas, mas é, sobretudo, construir um pensamento sobre o que é ver; sobre o que são nossos olhos como instrumentos condutores do ato de conhecer, levando-nos mesmo a acreditar que ver é conhecer o real, é ter esse real diante de nós.

Perguntamo-nos: e se o real fosse exatamente o real da imagem, e não aquele que estaria para além dela, representado por ela? Se assim fosse, a imagem impressa ou aparente nas telas estaria a nos dar o real no momento mesmo em que ele ganha existência. A imagem seria real, e o real não estaria (e estaria) na imagem.

Mas, para além de a imagem ser uma realidade em si mesma, ela nos faz mirar o mundo da maneira como ela o apresenta. A geógrafa Doreen Massey, no livro Pelo espaço, alerta-nos para a ação dos mapas no pensamento ocidental. Ao olharmos um mapa realizado sob as regras da cartografia ocidental, somos levados a imaginar o espaço geográfico como uma superfície lisa onde se dispõem lugares variados, nunca sobrepostos. Segundo essa mesma autora (2008, p. 258-260), o espaço geográfico deveria ser imaginado como "uma multiplicidade de estórias-até-aqui” articuladas e desarticuladas a um só tempo, onde os desencaixes são foco de negociaçôes devido às sobreposições dos territórios. Nesta maneira de imaginar o espaço geográfico, as imagens são também multiplicidades a serem consideradas no entendimento da atual configuração espacial e dos potenciais devires que cada lugar engendra.

Carlos Miranda, no artigo "A educação do olho", cita Walter Benjamin, quando afirma que "o cinema, a fotografia e todo aparato industrial de produ- 
ção de imagens e sons, ao invés de reproduzirem as condições naturais da percepção, alteram-nas.” (Miranda, 2001, p. 32). Carlos Miranda nos diz também que os filmes e as fotografias não nos mostram a percepção que temos do mundo com nossos próprios olhos; ao contrário, "trata-se de um outro olhar que reconstrói, a sua maneira, o real; e que nos proporciona uma outra experiência perceptiva." (idem, p. 39).

Podemos dizer que essas novas experiências de percepção estão postas em todas as linguagens criadoras de imagens e que estas criam miradas próprias para o mundo, para o real, para o espaço. Neste dossiê encontraremos artigos que se debruçam sobre duas tradições de mirada, cuja maior distinção é a perspectiva que assumem ao criar imagens do mundo: a perspectiva frontal de quem está de pé - e a perspectiva aérea - de quem olha do alto.

Uma dessas tradições é aquela na qual aquele que mira está em pé no chão horizontal criado pelas regras da perspectiva renascentista. Nela, o eixo espacial é dado pelo horizonte. Nessa tradição, quando a mirada desloca o observador da verticalidade humana em relação à superfície, o que está em foco é o deslocamento da posição tradicional, a produção de algum desequilíbrio, alguma estranheza. Cinema e pintura são os representantes dela neste dossiê.

$\mathrm{Na}$ outra dessas tradiçōes, encontraremos as fotografias aéreas, as imagens de satélite e os mapas. Imagens que nos colocam mirando o mundo de cima, do alto, chegando mesmo, nessa ascensão, a retirar-nos do mundo, como no caso dos mapas, que têm seu observador localizado num ponto chamado de infinito.

Ao grafar o espaço sob diferentes perspectivas, essas imagens desejam que miremos o espaço sob a perspectiva que elas nos dão dele. Buscam gestar e perpetuar uma maneira de imaginar o espaço. Nessa busca, elas também estão produzindo formas não só de imaginar o real, mas também de percebê-lo e concebê-lo. Elas nos educam o olho para ver sob determinada maneira e nessa esteira vão produzindo nossas memórias e as formas da nossa imaginação do real.

\section{A credibilidade das imagens}

Neste dossiê buscamos apontar traços das pedagogias inerentes às obras em imagens que circulam por nossa sociedade contemporânea. Como foi dito acima, entendemos que essas imagens não só nos dizem de nosso mundo, mas também nos educam a ler este mundo a partir delas. Legitimam, acima de tudo, a si mesmas como obras que dizem do real.

Tomo aqui o dizer num sentido amplo da utilização da linguagem, ou seja, não só em seu uso instrumental de comunicação, mas também e principal- 
mente, em seus múltiplos sentidos simbólicos, como os de tomar posse, nomear, tornar existente.

Muitas dessas imagens-que-dizem-do-mundo querem ser vistas como o próprio real manifestando-se diante de nós. Desejam ser tomadas como informaçôes-em-imagens passíveis de serem localizadas no mundo além-imagem.

É certo que essas informaçôes-em-imagens se tornam parte integrante do banco de imagens de que nos utilizamos para mover-nos no mundo, para pensálo. Provavelmente, muitos duvidarão do contexto midiático ou da pessoa que mostrou a imagem, fazendo com que esta fique sob suspeita. Não propriamente a imagem, mas a localização dela no discurso acerca do espaço, a localização dela na realidade espacial do planeta. Ou seja, normalmente não é a imagem que é colocada em suspeição, mas o veiculador que a apresentou como sendo de um lugar cuja imagem preexistente em nós é refratária àquela mostrada. Fotografias e filmes têm, em nossa cultura, esta aura de verdade irrefutável que algumas imagens nos trazem... tanto por manterem uma semelhança física visual e auditiva - com o real que "representam" quanto por acreditarmos que essa correspondência entre o objeto fotografado ou filmado e a fotografia ou o filme desse objeto seja fruto de um processo inevitável, disparado no momento exato em que se aperta o botão da máquina de captura. Os mapas também carregam em si esta aura de verdade irrefutável, mas não por verossimilhança ou processo ótico-químico instrumental, mas por credibilidade histórica nas fórmulas matemáticas que subjazem às obras cartográficas.

Em poucas palavras, duvidamos mais comumente da informação dada acerca da imagem do que de seu conteúdo visualizado, pois este nos chega como se fosse o próprio real dando-se a ver aos olhos humanos.

Essa crença na verdade mostrada pela imagem é ainda mais potente quando ela aparece num vídeo, e é ampliada quando essas imagens aparecem dentro de um programa que se propóe a documentar o real. Aqui falo diretamente dos documentários televisivos e dos telejornais. Na tevê, em geral, todas as imagens ganham o caráter de atualidade, inclusive as nitidamente ficcionais, como as novelas. Essas obras apresentam-se nas telinhas como a vida real contemporânea (ou de alguma época qualquer) "representada" por atores. Participam, assim, da construção da memória do presente.

Cabe um breve comentário sobre o motivo das aspas colocadas na idéia de representação. Representar, aqui, está no sentido de estar-no-lugar-de e não de ser-o-mesmo-que. No entanto, notadamente no que se refere às fotografias, aos filmes e às obras televisivas, esta distinção é quase sempre apagada, um sentido tornando-se o outro, o "não é" tornando-se "é". Isso porque o "não é" - estarno-lugar-de - e o "e’" - ser-o-mesmo-que - andam juntos nessas imagens, pois elas remetem a certas coisas e apresentam-nos essas tais coisas indiciadas visu- 
almente (e também auditivamente, no caso dos produtos audiovisuais) com forte verossimilhança à naturalidade com que as vemos e ouvimos no mundo além imagem. Mas seria importante chamar a atenção para a imagem como coisa em si, antes de ela remeter a outras que estão nela. Enquanto uma imagem for somente identificada com os índices visuais nela presentes (como uma representação), ela não conseguirá ser tomada como uma obra em si mesma, uma versão de mundo que diz do mundo no qual se insere, uma grafia deste mundo que é, sobretudo, um gesto na cultura.

Pelos parágrafos acima, podemos concluir que o grau de credibilidade das imagens - bem como o conteúdo confiável de cada imagem - é resultado de um processo complexo, no qual perpassam a natureza da imagem obtida por procedimentos mecânicos ou eletrônicos; a característica de representação da atualidade das imagens; e o compromisso com a verdade, assumido pelos contextos de comunicação onde essas imagens aparecem, seja uma conversa entre amigos, um telejornal, um livro didático, um artigo científico.

Mas a credibilidade não se ampara somente nesse tripé: penetra a própria linguagem com a qual as imagens são criadas ou postas narrativamente. Algumas dessas linguagens estão em foco neste dossiê: cinema, pintura, cartografia, aerofotogrametria e imageamento por satélite. Outras linguagens ficaram ao largo dos artigos. Por isso trago uma destas para esta apresentação: a fotografia.

\section{O lugar: fotografias e geografias}

Numa entrevista acerca de suas paisagens cristais ou refotografias, a artista Mônica Mansur diz que "a máquina não capta nem reflete, não revela nem imprime uma imagem, ela faz presente (presentifica) cada real".

$\mathrm{Na}$ esteira desse pensamento, ao tirar uma foto do local onde estamos, criamos mais do que um recorte em nosso mundo, no fato que está acontecendo, no momento em que estamos presentes. A máquina fotográfica, ao ser disparada, faz presente um real, ela o cria. Cada um escolhe um enquadramento para ver e, com essa foto em mãos, poderemos rememorar em outro local e em outro tempo o que vivemos ali. Mas o que rememoraremos não será a vida vivida no momento em que a foto foi feita, mas, sim, nossas lembranças tocarão aquele real criado pela câmera, pois é ele que estará presentificado no futuro da fotografia. Ao focalizar e disparar a máquina, adensamos todo o acontecimento, todo o momento, todo aquele local em torno desse recorte, dessa imagem fotografada? Adensamos, sim, todo aquele acontecimento, todo aquele momento, todo aquele local em torno desse recorte, dessa imagem fotografada. A imagem cria esse adensamento, produz um real.

Susan Sontag, no livro Diante da dor dos outros, diz que 
quando se trata de recordar, a fotografia fere mais fundo. A memória congela o quadro; sua unidade básica é a imagem isolada. Numa era sobrecarregada de informação, a fotografia oferece um modo rápido de apreender algo e uma forma compacta de memorizá-lo. A foto é como uma citação ou uma máxima ou um provérbio. (Sontag, 2006, p. 23)

É esta mesma autora quem irá nos alertar que "o problema não é que as pessoas lembrem por meio de fotos, mas que só se lembrem das fotos [...] [principalmente porque] lembrar, cada vez mais, não é recordar uma história, e sim ser capaz de evocar uma imagem." (idem, p. 75).

É neste caminho de pensamento - de que as nossas memórias acerca dos lugares medeiam nossas práticas espaciais nele desenvolvidas - que entendo a Geografia, e notadamente a Geografia Escolar, como aquele conhecimento que visa o entendimento das relações e das ações que homens e mulheres - crianças e jovens - travam com os lugares e seus elementos. Essas relações são aquelas que definem como agimos no espaço e, portanto, gestam a forma dos lugares, uma vez que eles ganham suas formas em função do uso que deles fazemos e da imagem que deles criamos a partir das memórias postadas em nós. Essas relações e memórias são formadas em nós tanto pelas experiências corporais diretas - aquelas valorizadas nos trabalhos de campo e nos estudos do meio - quanto pelas experiências mediadas pelas teorias ou por mídias diversas, notadamente as imagéticas. Estas últimas, cada vez mais, são responsáveis por uma grande quantidade dos conhecimentos e dos saberes - das memórias - que temos dos lugares.

É importante dizer que entendo essas relações travadas com o espaço geográfico, com seus lugares e processos, como sendo tanto econômicas e sociais quanto simbólicas, umas intervindo nas outras, com maior ou menor força, dependendo da situação social que vivemos, do grupo social a que pertencemos, do lugar de poder em que atuamos...

Se concluirmos que o lugar não é um dado em si, mas produto das tensões e das disputas entre as muitas práticas e narrativas que se dobram sobre ele, concluiremos também que, nos dias que correm, conhecer o espaço é também pensar sobre como ele é inventado diariamente diante de nós pelas câmeras fotográficas e pelas narrativas da tevê, e sobre como ele é criado em nossas próprias práticas educativas, onde aparecem muitos mapas, fotografias, filmes, pinturas e outras tantas imagens. 
Criar uma imagem do espaço é grafar um pensamento espacial, uma geo-grafia

O artista Arthur Omar escreveu que "toda obra é a transformação de outras obras, que se inscrevem anonimamente no seu corpo, é uma leitura de outras obras, e, ao mesmo tempo, dá a sua novidade como leitura para que outras obras se ramifiquem." (Omar, 1997, p. 201).

Este mesmo autor, no ensaio $O$ anti-documentário, toma as imagens como obras políticas, como gestos na cultura. Para ele, todo gesto na cultura é "a escolha de uma forma cultural" - filme, mapa, pintura, fotografia, etc. — que pretende apreender a realidade e fazê-la funcionar, em nossos pensamentos e imaginações, "como a realidade pretendida." (idem, p.197).

Numa perspectiva semelhante é que Doreen Massey, no já citado livro Pelo espaço, nos diz que os mapas, que são superfícies lisas, colocam a realidade espacial como uma superfície lisa, fazem-na funcionar assim em nossa imaginação do espaço. Esse modo de imaginar o espaço gera uma maneira de agir no território, de produzir territórios, de criar geografias para o mundo. Mas, se os lugares não forem somente pontos sobre uma superfície, mas, sim, um local onde se reúnem multiplicidades de trajetórias distintas e para onde convergem inúmeras práticas sociais e narrativas, tantas vezes solidárias quantas outras vezes discordantes, esses lugares não serão encaixáveis uns em relação aos outros num mapa que os mostraria a todos, simultaneamente coerentes; esses lugares terão, sim, zonas de encaixes e zonas de desencaixes, resultantes dos pensamentos discordantes em relação ao território, das geografias ali imaginadas e vividas. Geografias distintas que se embatem na busca de fazerem-se visíveis, legítimas, hegemônicas, reais...

Nessas disputas por dar existência ao seu modo de pensar o espaço, grupos e pessoas lançam mão de imagens para dar visibilidade pública - política - à geografia que pretendem seja tomada como a mais verdadeira, como sendo o real espacial existente para além das próprias imagens.

Essas imagens com conteúdos espaciais são gestos na cultura geográfica e desejam, em grande medida, criar imaginações que façam a realidade funcionar como a geografia ali apresentada em imagens.

Hannah Arendt, no livro $A$ vida do espirito, escreve que

a re-presentação, o fazer presente o que está de fato ausente, é o dom singular do espírito. E uma vez que toda a nossa terminologia é baseada em metáforas retiradas da experiência da visão esse dom é chamado de imaginação, definida por Kant como a faculdade da intuição mesmo sem a presença do objeto (1995, p. 60). 
No embate político por criar imaginações espaciais que tenham efeito de realidade, alguns verbos atinentes à experiência da visão cruzam nossas falas contemporâneas com sentidos e certezas de conhecer. Tributários de nossas práticas culturais voltadas a criar visualidades para o que está ausente, esses verbos, antes restritos a práticas sociais específicas, são usados como sinônimos dos verbos "ver", "entender" ou "compreender". "Fotografar" ou "mapear" não são mais verbos restritos ao ato de usar a máquina fotográfica ou aos princípios da cartografia para produzir uma imagem. Dizem respeito à alta credibilidade das imagens que lhes estão subjacentes - fotografias e mapas - e ao lugar que elas ocupam na produção do real. Para uma grande parte das pessoas, essas imagens não são obras humanas, mas a própria realidade impressa em papel ou visualizada na tela. Não é muito diferente o que ocorre com o uso do verbo "filmar" e com a relação que se estabelece com os filmes, principalmente os que se dizem documentários.

Ao assumir que a imagem presente numa fotografia, num mapa ou num filme é a realidade daquilo que ali se apresenta é que os verbos "fotografar", "mapear" e "filmar" se deslocam de seu universo técnico-cultural de produção para assumir um caráter mais objetivo existente nos verbos "capturar" e "mostrar"; um caráter mais evocativo existente no verbo "aludir"; um caráter mais persuasivo existente no verbo "representar"; ou mesmo, no limite, um caráter de substituição da coisa pela sua aparição imagética, quando usamos o verbo "ser": olhe como Campinas é, diz o professor, enquanto mostra aos seus alunos uma série de fotos, alguns mapas, um trecho de filme, uma imagem de satélite, uma pintura...

No entanto, verbos novos entram em cena para relativizar os sentidos que aqueles ganharam em nossa cultura. O melhor exemplo presente nos artigos deste dossiê é o do verbo "imagear". Subjacente ao sentido mais restrito deste verbo, ainda localizado nas práticas vinculadas às imagens de satélite e correlatas, há o sentido de que qualquer imagem produzida acerca do espaço não é o espaço, mas sim uma ação sobre ele que grafa um pensamento espacial. Dessa forma, a presença do verbo "imagear", descolada de seu campo restrito de uso atual, atuaria na relativização dos citados verbos que ascenderam à condição do verbo "ser", deslocando-os de volta aos seus sentidos técnico-culturais de produção humana, de ação sobre o mundo, de criação de mundos, de grafias do espaço... de espaços.

Estaríamos a reconhecer que o território não é a imagem que dele se produz, ao usar a expressão "imagear o espaço"? Estaríamos a assumir que produzir imagens sobre um espaço geográfico é criar uma versão imagética para ele, é criar territórios, é potencializar a existência de geografias nelas vistas e entrevistas? 


\section{Ruma a geografias menores}

No recente livro, A menor das ecologias, Ana Godoy fala sobre a produção de ecologias menores. Tomo os escritos presentes neste dossiê como geografias menores, dando a eles sentidos semelhantes aos que esta autora dá às menores das ecologias. Estas são resultantes de um processo de pensamento em "experimentação ativa: não se sabe de antemão aonde se vai chegar, tampouco quais encontros se darão pelo caminho" (Godoy, 2008, p. 52). Esta autora diz também que

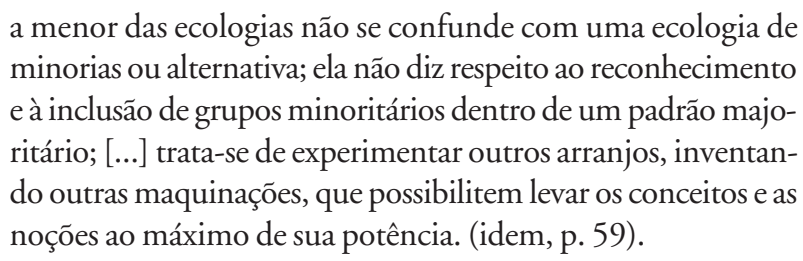

Conceitos e noções já presentes na tradição da ecologia [geografia] maior, ou então vindos de fora dela, trazidos pelas ecologias [geografias] menores gestadas nas maquinações e nos arranjos novos, inusitados. Dessa forma, é preciso tomar os artigos e os ensaios a seguir como geografias menores, como insinuações

em práticas que não são necessariamente reconhecidas como ecológicas [geográficas], fazendo com que as noções criadas pela ecologia [geografia] maior se tornem temas, pequenas peças que, em vez de significar - longe disso -, funcionam, como numa máquina: o que se faz é desmontá-los para extrair outras e novas tonalidades - fazê-los variar -, de maneira que a máquina, tal como Deleuze e Guattari a concebem, seja [...] menos uma crítica do que uma potência analítica das forças em combate. (idem, p. 60, destaques da autora).

Combate esse que se situa diante de nós como a possibilidade mesma de expandir os pensamentos que já circulam pela geografia maior, lembrando sempre que

a menor das ecologias [geografias] não corresponde a uma "boa" forma que se contraporia a uma "má" forma. Antes, ela remete a esta agitação molecular, subsistente na forma sem se adequar a ela, a uma potência de devir, que abala a forma, investindo força sobre a matéria que ela circunscreve. Toma-se a ecologia [geografia] como material de invenção, fazendo-a bifurcar e variar continuamente [...] [numa] deriva generalizada. (idem, p. 75, destaques da autora). 
Deriva-se, aqui, desde dentro da geografia maior, ao tomar o mapa, o tema ou a noção central, em muito da produção geográfica, como um objeto desejante, como o faz Gisele Girardi, ou como uma "ferramenta de conhecimento e produção do real que apresenta uma situação complexa que situa sobre um mesmo plano (metafórico) relações e elementos heterogêneos, processos sociais, políticos, mentais ou tecnológicos, acontecimentos, lugares, imaginários, etc.", como no dizer de José Pérez de Lama.

Deriva-se também de dentro da geografia maior, quando se tomam as técnicas de sensoriamento remoto, tão presentes nas obras geográficas contemporâneas, como aquelas que fizeram "nascer um tipo de conhecimento detalhado e, ao mesmo tempo, abrangente de porçóes da superfície terrestre, expressando, de certa forma, uma distinção entre escala geográfica e escala geométrica", como aponta Ricardo Castillo; ou, nas palavras de Valéria Cazetta, como "produtoras de imagens [que] recriam constantemente realidades acerca do espaço geográfico, impedindo-nos de afirmar que haveria uma realidade em si”.

Mas deriva-se, sobretudo, de fora, pelas margens, pelas bordas da geografia maior, quando se toma a linguagem pictórica, quase ausente das tradições geográficas, como centro do pensamento, e busca-se "perceber como ela permite ler determinado arranjo espacial”, como o faz Cláudio Benito Oliveira Ferraz, ou quando - como escreve Jörn Seemann - se toma uma única pintura, o quadro $O$ geógrafo, como obra que "pode ser considerada um retrato de como pensar e fazer geografia [em sua] época, mas também representa uma obra de arte com forte carga simbólica para estimular uma discussão metodológica sobre a leitura geográfica de imagens".

É também numa deriva exterior à geografia maior, aquela que toma o cinema e seus filmes como tema e engajamento, que surgem as proposições de tomar "a lei e o desejo como produtores da identidade de um lugar", como apontam James Craine e Giorgio Hadi Curti no artigo sobre o filme Tropa de elite, ou de assumir, a modo de Maria Helena Braga e Vaz da Costa, "que o cinema é capaz de construir e produzir novos espaços através da produção de novas visibilidades desses espaços".

Todas essas derivas buscam apontar devires possíveis ao pensamento geográfico a partir da potência que a mirada sobre as imagens traz até ele, atravessando-o com novas possibilidades de criação; com um punhado de geografias menores que brotam das colisões, dos embates e das aproximações entre os estudos que apontam a forte presença de uma educação pelas imagens nos dias atuais e os pensamentos acerca do espaço geográfico que surgem dela.

Este dossiê traz uma maneira de tomar o pensamento como vida; por isso, mais uma vez chamo Ana Godoy para acompanhar-me, para dizer com as palavras dela que "a potência deste pensamento é aquela da vida: expandir-se no 
experimentar a própria potência." (op.cit, p. 81-82). Deixo os leitores com nossas experimentações que se querem potentes para expandir-se em vida, em pensamento, em geografias.

\section{Referências bibliográficas}

ARENDT, Hannah. A vida do espírito: o pensar, o querer, o julgar. Rio de Janeiro: Relume Dumará, 1995.

GODOY, Ana. A menor das ecologias. São Paulo: EDUSP, 2008.

HARLEY, J. Brian. A nova história da cartografia. O Correio da Unesco. São Paulo, v. 19, n. 8 , p. 4-9, 1991.

LACOSTE, Yves. Geografia. In: CHÂTELET, François (Org). História da Filosofia - idéias, doutrinas. Rio de Janeiro: Zahar, 1981.v. 7.

MANSUR, Mônica. Paisagens cristais - refotografias. (maio de 2006). Disponível em: <http:/ /www.rioartecultura.com/monicamansur.htm>. Acesso em: 21 ago. 2009.

MASSEY, Doreen. Pelo espaço - uma nova política da espacialidade. Rio de Janeiro: Bertrand Brasil, 2008.

MIRANDA, Carlos et al. A educação do olho. Cadernos Cedes, Campinas, n. 54, p. 28-40, ago. 2001.

OMAR, Arthur. O antidocumentário, provisoriamente. Cinemais, Rio de Janeiro, p. 179-203, set./out. 1997. Editorial.

SONTAG, Susan. Diante da dor dos outros. São Paulo: Companhia das Letras, 2003.

TAVARES, Gonçalo. Breves notas sobre ciência. Lisboa: Relógio D’água, 2006. 